\title{
PENGARUH KEPEMIMPINAN TERHADAP PRODUKTIVITAS KERJA KARYAWAN BAGIAN MULTIFUEL BOILER PADA PT. LONTAR PAPYRUS PULP AND PAPER INDUSTRY
}

\author{
Sakinah AS, Anang Suprianto \\ Fakultas Ekonomi Universitas Batanghari
}

\begin{abstract}
The average increase in the number of employees Part Multifuel Boiler PT. Lontar Papyrus Pulp \& Paper Industry as much as 0.56\%. The average percentage of the absence of leadership in a meeting held in the last five years as much as $14.27 \%$. The average employee productivity developments Part Multifuel Boiler at PT. Lontar Papyrus Pulp \& Paper Industry at 31.333. Indicators for assessing leadership include: have a fairly high intelligence, stable emotions, face human intelligence, organizing skills and management skills. Indicators assessing productivity include: the ability, improve the results achieved, morale, selfdevelopment, quality and efficiency. PT. Lontar Papyrus Pulp \& Paper Industry which is a company engaged in Pulp \& Paper thats end product of PT. Lontar Papyrus Pulp \& Paper Industry, which in the final product the company is supported by Section Multifuel Boiler manage Steam Power ( Power Plant) to supply its electricity needs. Results SPSS 23 get the regression equation $Y=0.473$ $+0.892 X$. domination leadership on improving employee productivity Section Multifuel Boiler at PT. Lontar Papyrus Pulp \& Paper Industry as much as 76.9\% while the remaining $23.1 \%$ is caused by other factors. There is a significant relationship between the leadership on employee productivity Section Multifuel Boiler at PT. Lontar Papyrus Pulp \& Paper Industry. This statement proved of $t$ count 18.341 > t table value 1.9840 , with a significant $0.00<0.05$. Leadership and employee productivity Section Multifuel Boiler at PT. Lontar Papyrus Pulp \& Paper Industry high. According to test the hypothesis test is known that there is significant influence among the leadership on employee productivity Section Multifuel Boiler at PT. Lontar Papyrus Pulp and Paper Industry
\end{abstract}

Keyword : multifuel boiler, productivity

\section{PENDAHULUAN}

Manajemen sumber daya manusia adalah bagian dari manajemen atau dengan kata lain dapat dikatakan bahwa manajemen sumber daya manusia adalah suatu bidang manajemen yang khusus mempelajari hubungan dan peranan manusia dalam organisasi. Manajemen sumber daya manusia lebih memfokuskan pembahasannya mengenai pengaturan peranan manusia dalam mewujudkan tujuan yang optimal. Jelasnya manajemen sumber daya manusia mengatur tenaga kerja manusia sedemikian rupa sehingga terwujud tujuan organisasi.

Sumber daya manusia merupakan modal suatu organisasi baik organisasi pemerintahan maupun organisasi swasta untuk mencapai tujuan atau target yang ingin dicapai. Manusia merupakan unsur terpenting dalam setiap organisasi. Keberhasilan organisasi untuk mencapai tujuan dan sasarannya serta kemampuannya menghadapi berbagai tantangan, baik yang bersifat internal maupun yang bersifat eksternal ditentukan oleh sumber daya manusia yang baik.

Menyadari semakin pentingnya sumber daya manusia dalam suatu organisasi, maka pengelolaan sumber daya manusia perlu diperhatikan karena kunci sukses organisasi bukan hanya terbentuk pada tersediaanya modal yang 
cukup dan keunggulan saja, tapi lebih dari itu sangat tergantung pada sumber daya manusia.

Seseorang yang menduduki jabatan pemimpin atau manajerial dalam suatu organisasi memiliki pernanan yang sangat penting tidak hanya secara internal bagi organisasi yang bersangkutan akan tetapi juga dalam menghadapi berbagai pihak di luar organisasi yang kesemuanya dimaksudkan untuk meningkatkan kemampuan organisasi mencapai tujuannya. Keberhasilan seorang pemimpin dapat ditentukan oleh sifat-sifat, ciri-ciri yang dimiliki oleh pemimpin itu, dapat berupa sifat fisik atau sifat psikologis. Untuk menjadi seorang pemimpin yang berhasil sangat ditentukan kemampuan pribadi pemimpin itu sendiri. Kemampuan pribadi yang dimaksud adalah kualitas seseorang dengan berbagai macam sifatsifat, perangai atau ciri-ciri di dalamnya. Seorang yang menduduki pemimpin di dalam suatu organisasi mengemban tugas melaksanakan kepemimpinan. Dengan kata lain pemimpin adalah orang sedangkan kepemimpinan adalah kegiatannya. (Moeheriono, 2012:394).

Kepemimpinan dengan pendekatan baru sangat dibutuhkan untuk menghadapi perubahan yang sangat cepat, baik internal maupun di luar institusi. Dengan demikian dibutuhkan kepemimpinan yang bersifat transformatif, yaitu kepemimpinan yang mampu mengembangkan gerakan inovatif, mampu memberdayakan staf dan organisasi ke dalam suatu perubahan cara berpikir, pengembangan visi dan pemahaman tujuan organisasi serta membawa ke perubahan yang tidak henti-hentinya atau terus menerus dengan pengolahan aktivitas kerja dengan memanfaatkan bakat, keahlian, kemampuan ide dan pengalaman sehingga setiap pegawai merasa terlibat dalam menyelesaikan pekerjaan.

Kepemimpinan memiliki peran yang sangat penting dalam meningkatkan produktivitas kerja karyawannya. Dimana produktivitas kerja dapat ditinjau berdasarkan tingkatnya dengan tolak ukur masing - masing. Tolak ukur produktivitas kerja dapat dilihat dari kinerja atau prestasi kerja karyawan. Oleh karena itu diperlukan penilaian atas kinerja atau prestasi kerja karyawan untuk melihat dan meningkatkan produktivitas kerja karyawan.

Produktivitas merupakan hal yang sangat penting bagi para karyawan yang ada di perusahaan. Dengan adanya produktivitas diharapkan pekerjaan akan terlaksana secara efisien dan efektif, sehingga ini semua akhirnya sangat diperlukan dalam pencapaian tujuan yang telah ditetapkan.

Produktivitas kerja terdiri dari tiga aspek yaitu : pertama produktivitas adalah keluaran fisik per unit dari usaha produktif, kedua produktivitas merupakan tingkat keefektifan dari manajemen industri di dalam penggunaan fasilitas-fasilitas untuk produksi dan ketiga produktivitas adalah keefektifan dalam penggunaan tenaga kerja dan peralatan. (Sutrisno, 2011:102).

PT. Lontar Papyrus Pulp and Paper Industry yang merupakan perusahaan yang bergerak dibidang Pulp \& Paper yang menrupakan produk akhir dari PT. Lontar Papyrus Pulp and Paper Industry, dimana dalam menghasilkan produk akhir perusahaan ini disupport oleh Bagian MultiFuel Boiler dalam mengelola Pembangkit Listrik Tenaga Uap ( PLTU ) untuk memenuhi kebutuhan listriknya.

Jumlah karyawan pada PT. Lontar Papyrus Pulp and Paper Industry khususnya pada Bagian Multifuel Boiler dalam lima tahun terakhir dapat dilihat pada berikut ini : 
Tabel. 1

Jumlah Karyawan Bagian Multifuel Boiler

Pada PT. Lontar Papyrus Pulp and Paper Industry

Tahun 2011-2015

\begin{tabular}{ccc}
\hline Tahun & $\begin{array}{c}\text { Jumlah Karyawan } \\
\text { (orang) }\end{array}$ & $\begin{array}{c}\text { Persentase Perkembangan } \\
(\%)\end{array}$ \\
\hline 2011 & 104 & - \\
2012 & 109 & 4,81 \\
2013 & 98 & $(10,09)$ \\
2014 & 82 & $(16,33)$ \\
2015 & 102 & 24,39 \\
Rata-rata & 99 & 0,56 \\
\hline
\end{tabular}

Sumber : PT. Lontar Papyrus Pulp and Paper Industry, tahun 2016

Berdasarkan tabel diatas terlihat bahwa jumlah karyawan Bagian Multifuel Boiler pada PT. Lontar Papyrus Pulp and Paper Industry dalam lima tahun berfluktuasi. Rata-rata perkembangan jumlah karyawan Bagian Multifuel Boiler pada PT. Lontar Papyrus Pulp and Paper Industry sebanyak 0,56\%.

Kepemimpinan dapat tercermin dari kemampuan mengelola waktu terutama berkaitan dengan tingkat kehadiran dalam rapat yang diadakan di kantor. Seorang pemimpin pada tingkat manapun pada suatu waktu perlu mengadakan rapat dan memimpinnya (Sutrisno, 2011:230). Adapun tingkat kehadiran pimpinan dalam rapat pada PT. Lontar Papyrus Pulp and Paper Industry dalam lima tahun terakhir dapat terlihat pada tabel dibawah ini :

Tabel. 2.

Tingkat Kehadiran Pimpinan Dalam Rapat

Pada PT. Lontar Papyrus Pulp and Paper Industry Tahun 2011-2015

\begin{tabular}{lccccc}
\hline Tahun & $\begin{array}{c}\text { Jumlah } \\
\text { Rapat } \\
\text { (kali) }\end{array}$ & $\begin{array}{c}\text { Kehadiran } \\
\text { (kali) }\end{array}$ & $\begin{array}{c}\text { Persentase } \\
\text { Kehadiran } \\
(\boldsymbol{\%})\end{array}$ & $\begin{array}{c}\text { Ketidakhadiran } \\
\text { (kali) }\end{array}$ & $\begin{array}{c}\text { Persentase } \\
\text { Ketidakhadiran } \\
(\%)\end{array}$ \\
\hline 2011 & 63 & 53 & 84,13 & 10 & 15,87 \\
2012 & 58 & 50 & 86,21 & 8 & 13,79 \\
2013 & 60 & 48 & 80,00 & 12 & 20 \\
2014 & 67 & 51 & 76,12 & 4 & 5,97 \\
2015 & 70 & 59 & 84,29 & 11 & 15,71 \\
Rerata & 64 & 52 & 84.29 & 9 & 14,27 \\
\hline
\end{tabular}

Sumber : PT. Lontar Papyrus Pulp and Paper Industry, tahun 2016

Berdasarkan tabel diatas diketahui bahwa perilaku kepemimpinan pada PT. Lontar Papyrus Pulp and Paper Industry terkait dengan tingkat kehadiran dalam rapat yang diadakan di kantor dalam lima tahun terakhir masih perlu diperbaiki. Rata-rata persentase ketidakhadiran pimpinan dalam rapat yang diadakan dalam lima tahun terakhir sebanyak $14,27 \%$.

Sementara itu perkembangan karyawan, banyaknya produksi Multifuel Boiler (MB) serta produktivitas pada PT. Lontar Papyrus Pulp and Paper Industry dalam lima tahun terakhir dapat terlihat pada tabel dibawah ini : 
Tabel. 3.

Perkembangan Karyawan, Produksi Multifuel Boiler (MB) dan Produktivitas Pada PT. Lontar Papyrus Pulp and Paper Industry

Periode 2011 - 2015

\begin{tabular}{cccc}
\hline Tahun & $\begin{array}{c}\text { Jumlah Karyawan } \\
\text { (Orang) }\end{array}$ & $\begin{array}{c}\text { Produksi MB } \\
\text { (ton) }\end{array}$ & $\begin{array}{c}\text { Produktivitas } \\
\text { MB/orang }\end{array}$ \\
\hline 2011 & 104 & $2,997,242$ & 28,820 \\
2012 & 109 & $3,559,720$ & 32,658 \\
2013 & 98 & $3,980,817$ & 40,621 \\
2014 & 82 & $2,609,820$ & 31,827 \\
2015 & 102 & $2,319,530$ & 22,740 \\
Rata-rata & 99 & $3,093,426$ & 31,333 \\
\hline
\end{tabular}

Sumber : PT. Lontar Papyrus Pulp and Paper Industry, tahun 2016

Dari tabel diatas dapat terlihat selama kurun waktu 2011 - 2015 perkembangan produktivitas karyawan Bagian MultiFuel Boiler pada PT. Lontar Papyrus Pulp and Paper Industry dalam lima tahun terakhir berfluktuasi. Rata-rata perkembangan produktivitas karyawan Bagian MultiFuel Boiler pada PT. Lontar Papyrus Pulp and Paper Industry sebesar 31,333.

Kepemimpinan memainkan peran yang dominan, krusial dan kritikal dalam keseluruhan upaya untuk meningkatkan produktivitas kerja, baik pada tingkat individual, pada tingkat kelompok dan pada tingkat organisasi. Demi peningkatan produktivitas kerja diperlukan kepemimpinan yang tangguh yang sekaligus berperan sebagai manajer yang handal.

Berdasarkan keterangan tersebut diatas maka penulis tertarik untuk mengkaji lebih jauh pengaruh kepemimpinan terhadap produktivitas kerja. Penelitian ini dalam bentuk tulisan skripsi dengan judul " Pengaruh Kepemimpinan Terhadap Produktivitas Kerja Karyawan Bagian MultiFuel Boiler Pada PT. Lontar Papyrus Pulp and Paper Industry “.

Berdasarkan latar belakang yang dikembangkan diatas, maka ditemukan identifikasi masalah sebagai berikut : 1) Jumlah karyawan Bagian Multifuel Boiler pada PT. Lontar Papyrus Pulp and Paper Industry berfluktuasi. 2) Tingkat kehadiran pimpinan dalam rapat relatif masih rendah. 3) Produksi Multifuel Boiler (MB) pada PT. Lontar Papyrus Pulp and Paper Industry berfluktuasi. 4) Produktivitas kerja karyawan Bagian MultiFuel Boiler pada PT. Lontar Papyrus Pulp and Paper Industry berfluktuasi.

Rumusan yang didapat dalam latar belakang terlalu banyak untuk dijadikan penelitian, maka penulis merumuskan masalah yang diambil dalam penelitian ini adalah : 1) Bagaimana kepemimpinan dan produktivitas kerja karyawan Bagian MultiFuel Boiler pada PT. Lontar Papyrus Pulp and Paper Industry ? 2) Bagaimana pengaruh kepemimpinan terhadap produktivitas kerja karyawan Bagian MultiFuel Boiler pada PT. Lontar Papyrus Pulp and Paper Industry ?

Adapun tujuan penelitian ini adalah sebagai berikut : 1) Untuk mengetahui kepemimpinan dan produktivitas kerja karyawan Bagian MultiFuel Boiler PT. Lontar Papyrus Pulp and Paper Industry. 2) Untuk menganalisis pengaruh kepemimpinan terhadap produktivitas kerja karyawan Bagian MultiFuel Boiler PT. Lontar Papyrus Pulp and Paper Industry. 


\section{TINJAUAN PUSTAKA}

\section{Kepemimpinan}

Menurut Simanjuntak (2011:271) kepemimpinan adalah proses psikologis dalam menerima tanggung jawab tugas, diri sendiri dan nasib orang lain.

Menurut Rivai (2003:36) kepemimpinan adalah proses untuk mempengaruhi orang lain, baik di dalam organisasi maupun di luar organisasi untuk mencapai tujuan yang diinginkan dalam suatu situasi dari kondisi tertentu.

Menurut Suwatno (2011:140) kepemimpinan adalah kemampuan untuk memberikan pengaruh yang konstruktif kepada orang lain untuk melakukan satu usaha kooperatif mencapai tujuan yang yang sudah direncanakan.

Menurut Moeheriono (2012:39) ada tiga hal penting yang harus dimiliki seorang pemimpin, yaitu :

\section{a. Kekuasaan}

Otorisasi dan legalitas yang memberikan wewenang kepada pemimpin untuk mempengaruhi dan menggerakkan bawahan untuk berbuat sesuatu dalam rangka penyelesaian tugas tertentu.

b. Kewibawaan

Keunggulan, kelebihan, keutamaan sehingga pemimpin mampu mengatur orang lain dan patuh kepadanya.

c. Kemampuan

Sumber daya kekuatan, kesanggupan dan kecakapan secara teknis maupun sosial yang melebihi dari anggota biasa.

Dalam melaksanakan kepemimpinan terdapat beberapa unsure yang perlu diperhatikan. Menurut Wilson (2012:340) ada empat unsur dalam kepemimpinan antara lain :

a. Kumpulan orang

Para pengikut akan menerima pengarahan dan perintah dari pemimpin. Tanpa adanya kelompok sebagai pengikut dalam organisasi, maka kepemimpinan tidak akan terwujud.

b. Kekuasaan

Kekuasaan merupakan kekuatan yang dimiliki oleh seorang pemimpin untuk mempengaruhi para pengikutnya dalam melaksanakan tugasnya. Ada lima dasar kekuasaan yang dimiliki pemimpin yaitu kekuasaan menghargai, kekuasaan memaksa, kekuasaan sah, kekuasaan rujukan dan kekuasaan keahlian.

c. Mempengaruhi

Para pemimpin memiliki kualitas daya tarik yang dapat menimbulkan kesetiaan, pengabdian dan keinginan yang kuat dari anggota organisasi untuk melakukan hal yang diinginkan pemimpin.

d. Nilai

Kemampuan untuk menggunakan tiga unsur sebelumnya adalah kemampuan untuk menggunakan berkaitan dengan nilai.

Dalam rangka mencapai efektivitas kepemimpinan maka perlu mengetahui dan menguasai tehniknya. Menurut Meheriono (2012:394) ada beberapa tehnik kepemimpinan yang harus dikuasai seorang pemimpin, meliputi :

a. Memahami etika profesi pemimpin 
Kewajiban yang dimiliki seorang pemimpin memahami bagaimana seharusnya tingkah laku seorang pemimpin dan mengembangkan moralnya.

b. Memahami dinamika kelompok

Terjadinya interaksi (hubungan timbal balik) antar setiap anggota organisasi.

c. Memahami komunikasi

Arus infromasi dan emosi yang tepat, penyampaian perasaan, pikiran dan kehendak kepada individu (kelompok) lain.

d. Memahami pengambilan keputusan

Suatu hal yang sangat penting bagi seorang pemimpin walaupun sebenarnya cukup sulit.

e. Memahami keterampilan berdiskusi (melakukan kompromi)

Bertujuan untuk memecahkan masalah untuk mencari jalan keluar dengan mengambil kesimpulan.

Kepemimpinan seseorang dapat terlihat dari gaya kepemimpinannya. Menurut Rasyid (2002:111) ada 4 karakter kepemimpinan antara lain dapat diuraikan sebagai berikut :

a. Kepemimpinan yang sensitif

Ditandai dengan kemampuan untuk secara dini memahami dinamika perkembangan masyarakat, mengerti apa yang mereka butuhkan serta mengusahakan agar ia menjadi pihak pertama yang memberi perhatian terhadap kebutuhan itu.

b. Kepemimpinan responsif

Ditandai dengan menghayati suatu sikap untuk mendengar suara pengikutnya, mau menggunakan energi dan waktunya untuk secara cepat menjawab pertanyaan, menampung setiap keluhan, memperhatikan setiap tuntutan dan memanfaatkan setiap dukungan.

c. Kepemimpinan Defensif

Ditandai dengan sikap egoistik, merasa paling benar walaupun pada saat yang sama memiliki kemampuan argumentasi yang tinggi dalam berhadapan dengan pengikutnya.

d. Kepemimpinan yang represif

Karakternya cenderung sama egois dan arogannya dengan karakter yang defensif. Tetapi ia lebih buruk lagi karena tidak memiliki kemampuan argumentasi atau justifikasi dalam mempertahankan keputusan atau penilaiannya terhadap suatu isu ketika berhadapan dengan pengikutnya.

Dalam menilai dan mengevaluasi kepemimpinan perlu dapat dilihat dari indikator penilaian. Menurut Rivai (2003:123) indikator kepemimpinan yang efektif antara lain :

a. Mempunyai kecerdasan yang cukup tinggi untuk dapat memikirkan dan mencarikan cara-cara pemecahan setiap persoalan yang timbul dengan cara yang tepat, bijaksana serta mengandung kelengkapan dan syarat-syarat yang memungkinkan untuk dilaksanakan.

b. Mempunyai emosi yang stabil

c. Mempunyai kepandaian dalam menghadapi manusia dan mampu membuat bawahan merasa betah, senang dan puas dengan pekerjaannya.

d. Mempunyai keahlian untuk mengorganisasi dan menggerakkan bawahan secara bijaksana

e. Mempunyai keterampilan manajemen untuk menghadapi persoalan masyarakat. 


\section{Produktivitas}

Menurut Sedarmayanti (2009:57) produktivitas adalah perbandingan antara hasil yang dicapai (output) dengan keseluruhan sumber daya yang digunakan (input).

Menurut Sutrisno (2011:102) produktivitas kerja adalah rasio dari hasil kerja dengan waktu yang dibutuhkan untuk menghasilkan produk dari seorang tenaga kerja.

Sedangkan Dewan Produktivitas Nasional memberikan pengertian produktivitas sebagai sikap mental yang selalu berpandangan bahwa mutu kehidupan hari ini harus lebih baik dari kemarin dan hari esok harus lebih baik dari hari ini.

Dalam menilai dan mengevaluasi produktivitas dapat ditinjau dari beberapa indikator. Indikator untuk mengukur tingkat produktivitas kerja antara lain (Sutrisno, 2011:104) :

a. Kemampuan

Mempunyai kemampuan untuk melaksanakan tugas. Kemampuan seorang karyawan sangat bergantung pada keterampilan yang dimiliki serta profesionalisme mereka dalam bekerja.

b. Meningkatkan hasil yang dicapai

Berusaha untuk meningkatkan hasil yang dicapai. Hasil merupakan salah satu yang dirasakan baik oleh yang mengerjakan maupun yang menikmati hasil pekerjaan tersebut.

c. Semangat kerja

Ini merupakan usaha untuk lebih baik dari hari kemarin. Indikator ini dapat dilihat dari etos kerja dan hasil yang dicapai dalam satu hari kemudian dibandingkan dengan hari sebelumnya.

d. Pengembangan diri

Senantiasa mengembangkan diri untuk meningkatkan kemampuan kerja. Pengembangan diri dapat dilakukan dengan melihat tantangan dan harapan dengan apa yang akan dihadapi.

e. Mutu

Selalu berusaha untuk meningkatkan mutu lebih baik dari yang telah lalu. Mutu merupakan hasil pekerjaan yang dapat menunjukkan kualitas kerja seorang pegawai.

f. Efisiensi

Perbandingan antara hasil yang dicapai dengan keseluruhan sumber daya yang digunakan. Masukan dan keluaran merupakan aspek produktivitas yang memberikan pengaruh yang cukup signifikan bagi karyawan.

\section{Hubungan Antara Kepemimpinan dengan Produktivitas}

Sumber daya manusia dalam perusahaan perlu dikelola dengan secara profesional agar terwujud keseimbangan antara kebutuhan karyawan dengan tuntutan dan kemampuan perusahaan. Keseimbangan tersebut merupakan kunci utama perusahaan agar dapat berkembang secara produktif.

Sinungan (2007:15) yang menyatakan bahwa kepemimpinan yang termasuk di dalam lingkungan organisasi merupakan faktor potensi dalam meningkatkan produktivitas kerja.

Selanjutnya Timple (2009:31) menyatakan bahwa pemimpin adalah orang yang menerapkan prinsip dan teknik yang memastikan motivasi, disiplin dan produktivitas jika bekerja sama dengan orang, tugas dan situasi dapat mencapai sasaran perusahaan. 
Dari pengertian diatas dapat disimpulkan bahwa tugas pemimpin adalah mengideintifikasi dan memotivasi karyawan agar dapat berprestasi dengan baik dan pada akhirnya akan meningkatkan produktivitas perusahaan.

\section{Kerangka Pemikiran}

Indikator untuk menilai kepemimpinan meliputi : mempunyai kecerdasan yang cukup tinggi, emosi yang stabil, kepandaian menghadapi manusia, keahlian mengorganisasi serta keterampilan manajemen. (Rivai, 2003:123). Indikator menilai produktivitas meliputi : kemampuan, meningkatkan hasil yang dicapai, semangat kerja, pengembangan diri, mutu serta efisiensi. (Sutrisno, 2011:104)

Agar lebih memudahkan memahami keterangan diatas maka dapat dilihat pada bagan kerangka pemikiran berikut ini :

\begin{tabular}{|c|c|}
\hline $\begin{array}{c}\text { Kepemimpinan } \\
\text { X }\end{array}$ & $\begin{array}{c}\text { Produktivitas } \\
\text { Y }\end{array}$ \\
\hline $\begin{array}{l}\text { 1. Mempunyai kecerdasan yang } \\
\text { cukup tinggi } \\
\text { 2. Emosi yang stabil } \\
\text { 3. Kepandaian menghadapi } \\
\text { manusia } \\
\text { 4. Keahlian mengorganisasi } \\
\text { 5. Keterampilan manajemen } \\
\text { ( Rivai, } 2003 ; 123 \text { ). }\end{array}$ & $\begin{array}{l}\text { 1. Kemampuan } \\
\text { 2.Meningkatkan hasil yang } \\
\text { dicapai } \\
\text { 3. Semangat kerja } \\
\text { 4. Pengembangan diri } \\
\text { 5. Mutu } \\
\text { 6. Efisiensi } \\
\text { (Sutrisno, 2011: 104) }\end{array}$ \\
\hline
\end{tabular}

\section{Hipotesis}

1. Diduga kepemimpinan baik dan produktivitas kerja karyawan Bagian MultiFuel Boiler pada PT. Lontar Papyrus Pulp and Paper Industry tinggi.

2. Diduga kepemimpinan berpengaruh signifikan terhadap produktivitas kerja karyawan Bagian MultiFuel Boiler pada PT. Lontar Papyrus Pulp and Paper Industry.

\section{METODE PENELITIAN}

Metode penelitian yang digunakan adalah penelitian deskriptif kualitatif, dengan menggunakan data primer dan sekunder yang bersumber dari PT. Lontar Papyrus Pulp and Paper Industry. Adapun sampel data karyawan bagian MultiFuel Boiler pada PT. Lontar Papyrus Pulp and Paper Industry. Sedangkan analisis data menggunakan Analisis Regresi Sederhana diolah dengan program SPSS versi 23. Karena data bersifat ordinal, maka terlebih dahulu digunakan dengan program MSI. Selanjutnya analisis data menggunakan Koefisien Korelasi, Koefisien Determinasi, sedangkan uji statistik dengan Uji t.

\section{Operasional Variabel}

Operasional variabel berisi tabel-tabel tentang uraian setiap variabel penelitian menjadi dimensi-dimensi, dan dari dimensi - dimensi menjadi indikator-indikatornya. Setiap indikator ditetapkan satuan pengukuran serta skala pengukurannya. (Umar, 2013:168). 


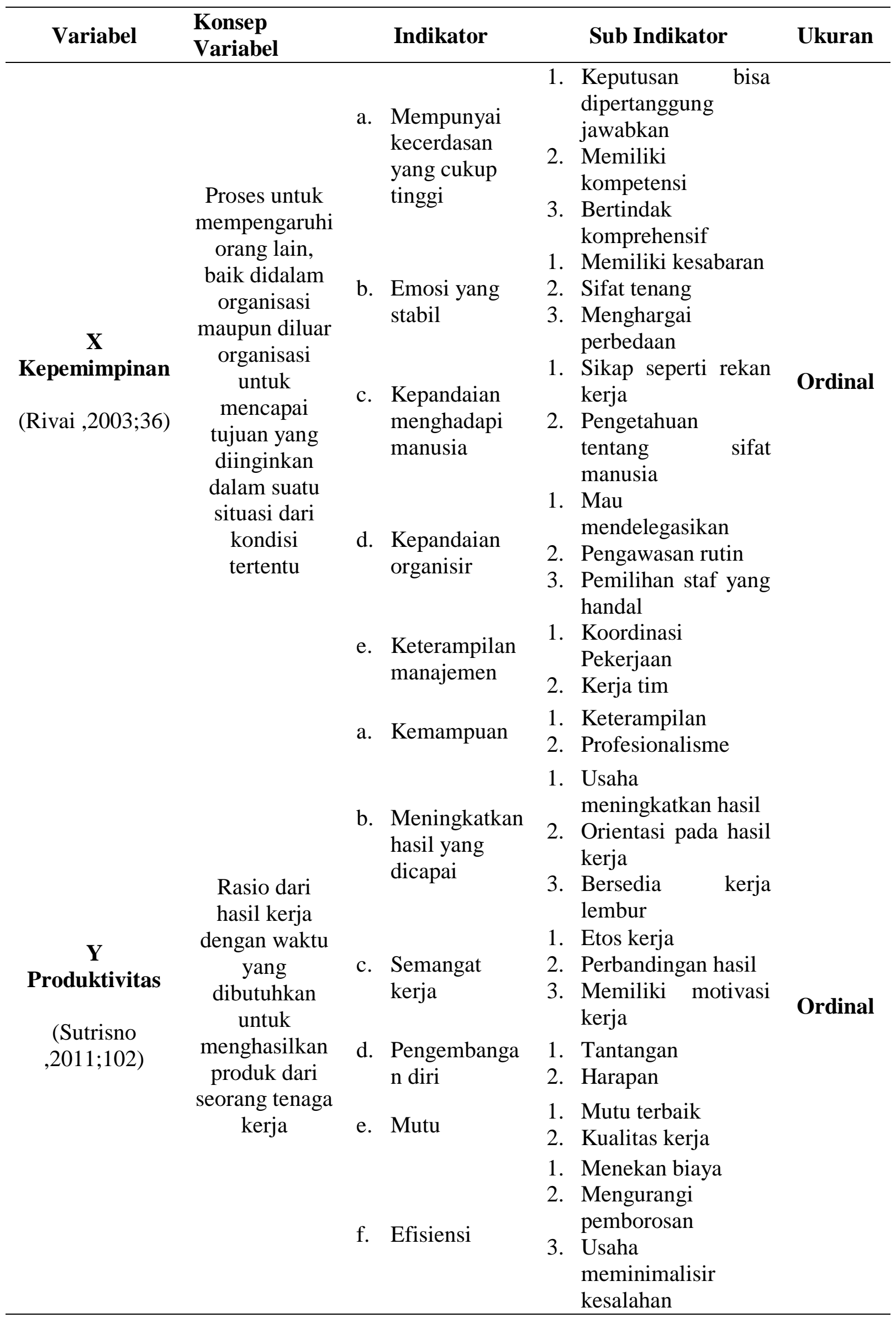




\section{HASIL DAN PEMBAHASAN}

\section{Pengaruh Kepemimpinan Terhadap Produktivitas Karyawan}

\section{Persamaan Regresi}

Pengaruh kepemimpinan terhadap produktivitas kerja karyawan Bagian MultiFuel Boiler pada PT. Lontar Papyrus Pulp and Paper Industry berdasarkan perhitungan SPSS 23 dapat dilihat sebagai berikut :

$$
Y=0,473+0,892 X
$$

Koefisien variabel kepemimpinan sebesar 0,892 artinya jika kepemimpinan mengalami kenaikan sebesar $1 \%$ maka produktivitas karyawan akan mengalami kenaikan sebesar 0,892.

Konstanta sebesar 0,473 artinya jika variabel kepemimpinan konstan, maka produktivitas kerja karyawan Bagian MultiFuel Boiler pada PT. Lontar Papyrus Pulp and Paper Industry sebesar 0,473.

\section{Koefisien Determinasi $\left(\mathbf{R}^{2}\right)$}

Dari hasil pengujian determinasi maka diperoleh nilai adjusted $\mathrm{R}^{2}$ sebesar 0,769 angka ini menyatakan bahwa variabel $\mathrm{X}$ atau kepemimpinan mampu menjelaskan variabel $\mathrm{Y}$ atau produktivitas kerja karyawan Bagian MultiFuel Boiler pada PT. Lontar Papyrus Pulp and Paper Industry sebesar 76,9 \% sebaliknya 23,1\% disebabkan oleh variabel lain di luar variabel yang diteliti.

\section{Koefisien Korelasi}

Koefisien korelasi antara kepemimpinan terhadap produktivitas karyawan Bagian MultiFuel Boiler pada PT. Lontar Papyrus Pulp and Paper Industry adalah 0,878, artinya terdapat hubungan yang sangat erat antara variabel $\mathrm{X}$ atau kepemimpinan dan $\mathrm{Y}$ atau produktivitas karyawan.

\section{Uji Hipotesis}

Berdasarkan hasil perhitungan diperoleh angka $t_{\text {hitung }}$ 18,341 sedangkan $\mathrm{t}_{\text {tabel }}$ sebesar 1,9840. Jadi $\mathrm{t}_{\text {hitung }} 18,341>\mathrm{t}_{\text {tabel }} 1,9840$. Maka keputusannya Ho ditolak dan Ha diterima. Dengan demikian ada pengaruh signifikan antara kepemimpinan terhadap produktivitas karyawan Bagian MultiFuel Boiler pada PT. Lontar Papyrus Pulp and Paper Industry.

\section{SIMPULAN}

Berdasarkan pembahasan pada bab-bab sebelumnya maka dapat ditarik beberapa kesimpulan sebagai berikut :

1. Kepemimpinan dan produktivitas karyawan Bagian MultiFuel Boiler pada PT. Lontar Papyrus Pulp and Paper Industry tinggi.

2. Berdasarkan test uji hipotesis diketahui bahwa terdapat pengaruh signifikan antara kepemimpinan terhadap produktivitas karyawan Bagian MultiFuel Boiler pada PT. Lontar Papyrus Pulp and Paper Industry

\section{DAFTAR PUSTAKA}

Danang, Sunyoto, 2013, Teori, Kuesioner dan Analisis Data Sumber Daya Manusia, CAPS, Jakarta

Bangun, Wilson, 2012, Manajemen Sumber Daya Manusia, Penerbit Erlangga, Jakarta

Fathoni, Ahmad, 2006, Sumber Daya Manusia dan Produktivitas Kerja, CV. Mandar Maju, Bandung

Kurniawan, Albert, 2009, Belajar Mudah SPSS, PT. Buku Kita, Jakarta

Mangkunegara, Anwar Prabu, 2008, Manajemen Sumber Daya Manusia, PT. Remaja Rosdakarya, Bandung 
Handoko, T. Hani, 2005, Manajemen, PT. Ghalia Indonesia, Jakarta

Hasibuan, Malayu S.P, 2009, Manajemen Sumber Daya Manusia, Penerbit Toko Gunung Agung, Jakarta

Istijanto . 2009. Aplikasi Riset. PT. Gramedia Pustaka Utama. Jakarta

Kasmir, 2016, Manajemen Sumber Daya Manusia, PT. RajaGrafindo Persada, Jakarta

Moeheriono, 2012, Pengukuran Kinerja Berbasis Kompetensi, PT. RajaGrafindo Persada, Jakarta

Rasyid, Muhammad, 2002, Gaya Kepemimpinan, PT. RajaGrafindo, Jakarta

Rivai, Veithzal, 2003, Kepemimpinan dan Perilaku Organisasi, PT. RajaGrafindo

Sarwono, Jonathan, 2012, Metode Riset Skripsi Pendekatan Kuantitatif, PT. Elex Media Komputindo, Jakarta

Sedarmayanti, 2009, Sumber Daya Manusia dan Produktivitas Kerja, CV. Mandar Maju, Bandung

Simamora, 2007, Manajemen Kepegawaian, Ghalia, Jakarta

Simanjuntak, Payaman, 2011, Manajemen dan Evaluasi Kerja, Lembaga Penerbit Fakultas Ekonomi Universitas Indonesia, Jakarta

Sinungan, 2007, Manajemen Sumber Daya Manusia, Kencana Prenada Media Group, Jakarta

Sugiyono, 2010, Statistika Untuk Penelitian, Alfabeta, Bandung

Supardi, 2013, Aplikasi Statistika Dalam Penelitian, Change Publication, Jakarta

Sutrisno, Edy, 2011, Manajemen Sumber Daya Manusia, Kencana Prenada Media Group, Jakarta

Suwatno, 2011, Manajemen Sumber Daya Manusia, CV. Alfabeta, Bandung

Syekh, Sayid, 2011, Pengantar Statistik Ekonomi, Gaung Pesada Press, Jakarta

Timple, Dale, 2007, Manajemen Sumber Daya Manusia, Penerbit Erlangga, Jakarta

Umar, Husin, 2013, Desain Penelitian MSDM dan Perilaku Karyawan, PT. RajaGrafindo, Jakarta 